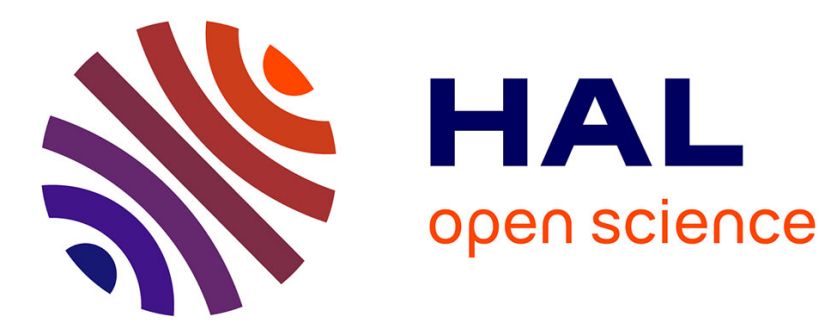

\title{
Stepping in Persons Poststroke: Comparison of Voluntary and Perturbation-Induced Responses
}

Katherine M. Martinez, Marie-Laure Mille, Yunhui Zhang, Mark W. Rogers

\section{To cite this version:}

Katherine M. Martinez, Marie-Laure Mille, Yunhui Zhang, Mark W. Rogers. Stepping in Persons Poststroke: Comparison of Voluntary and Perturbation-Induced Responses. Archives of Physical Medicine and Rehabilitation, 2013, 94 (12), pp.2425-2432. 10.1016/j.apmr.2013.06.030 . hal-01438451

\section{HAL Id: hal-01438451 \\ https://hal.science/hal-01438451}

Submitted on 17 May 2018

HAL is a multi-disciplinary open access archive for the deposit and dissemination of scientific research documents, whether they are published or not. The documents may come from teaching and research institutions in France or abroad, or from public or private research centers.
L'archive ouverte pluridisciplinaire HAL, est destinée au dépôt et à la diffusion de documents scientifiques de niveau recherche, publiés ou non, émanant des établissements d'enseignement et de recherche français ou étrangers, des laboratoires publics ou privés. 


\title{
ORIGINAL ARTICLE
}

\section{Stepping in Persons Poststroke: Comparison of Voluntary and Perturbation-Induced Responses}

\author{
Katherine M. Martinez, PT, MA, ${ }^{a}$ Marie-Laure Mille, PhD, ${ }^{b, c, d}$ Yunhui Zhang, MS, ${ }^{a}$ \\ Mark W. Rogers, PT, PhD ${ }^{\mathrm{d}}$
}

From the ${ }^{a}$ Department of Physical Therapy and Human Movement Sciences, Feinberg School of Medicine, Northwestern University, Chicago, IL; ${ }^{b}$ Aix-Marseille Université, CNRS, ISM UMR 7287, Marseille; ' Université Sud Toulon-Var, La Garde, France; and 'Department of Physical Therapy and Rehabilitation Science, University of Maryland School of Medicine, Baltimore, MD.

\begin{abstract}
Objectives: To examine the stepping performance during voluntary and waist-pull perturbation-induced step initiation in people with chronic stroke.

Design: Repeated-measures single-case design.

Setting: University-based research laboratory.

Participants: Community-dwelling stroke survivors $(\mathrm{N}=10)$.

Interventions: Not applicable.

Main Outcome Measures: Ground reaction forces and kinematic data were recorded to assess anticipatory postural adjustments (APAs) and step characteristics for both voluntary and induced stepping conditions.

Results: Induced stepping was performed with both the paretic (35\% trials) and nonparetic legs (65\% trials). Induced first steps occurred earlier and were executed faster than rapid voluntary steps. Compared with voluntary stepping, induced first step APAs were shorter in duration. Step height was higher with the nonparetic leg for both stepping conditions. Use of the paretic leg increased (52\%) during the diagonal perturbations that passively unloaded the stepping limb compared with the use of the paretic leg (33\%) for forward perturbations.

Conclusions: The results indicated differences in executing voluntary and induced stepping, and between the paretic and nonparetic limbs in individuals with chronic stroke. The findings suggested guidelines for using stepping as a component of neurorehabilitation programs for enhancing balance and mobility. Additional larger-scale studies remain to be undertaken to further investigate these issues.

Archives of Physical Medicine and Rehabilitation 2013;94:2425-32
\end{abstract}

(c) 2013 by the American Congress of Rehabilitation Medicine

Diminished balance function leading to instability and falls is a common and frequently debilitating secondary complication after stroke. Ambulatory individuals with chronic stroke are especially vulnerable to falling because of balance and mobility impairments. Although falls are multivariate problems involving a large number of intrinsic and extrinsic risk factors, the ability to

Presented (preliminary results) to the American Physical Therapy Association, June 6-9, 2012, Tampa Bay, FL.

Supported by the Foundation for Physical Therapy, which provided funding for the Physical Therapy Clinical Research Network (PTClinResNet) and supported the STEPS clinical research project at Northwestern University, which provided access to subjects for this study.

No commercial party having a direct financial interest in the results of the research supporting this article has conferred or will confer a benefit on the authors or on any organization with which the authors are associated. effectively maintain balance while standing, during transfer activities, and while walking on varied terrain is importantly related to avoiding falls and related injuries after stroke. Protective movements of the limbs such as stepping and grasping firm surfaces in the environment are normally often used to stabilize balance by altering the body's center of mass (COM)-base of support (BOS) relationship. ${ }^{1-3}$ Grasping may be a more limited option after stroke because the nonparetic arm is frequently engaged with an assistive device. Thus, protective stepping is likely a more prevalent strategy. ${ }^{1,2}$

Altering the BOS through stepping can occur in reaction to an external postural perturbation, or voluntarily in anticipation of a perceived threat to stability. Among older adults, impairments of both forms of stepping have been linked with falls. ${ }^{4,5}$ Given the 
greater incidence of falls poststroke compared with that in healthy older adults, ${ }^{6}$ it is conceivable that similar relationships may exist between stepping performance and fall risk. ${ }^{3}$

From a neuromotor control standpoint, perturbation-induced and voluntary stepping normally differ in several respects. ${ }^{5,7}$ Specifically, induced stepping is often more rapidly initiated and executed than rapid voluntary stepping. Moreover, instructed, stimulus-cued voluntary stepping involving task certainty engages central motor planning and preparation that are less likely involved with perturbation-induced stepping, especially where subjects are not preinstructed to step or the perturbation conditions are not known in advance, or both. Also, anticipatory postural adjustments (APAs) for lateral weight transfer and mediolateral balance stability before stepping occur less often and are reduced in magnitude and duration for induced stepping compared with voluntary stepping. These observations suggest normal differences in the neuromotor control mechanisms underlying the 2 types of stepping that could be differentially affected by stroke.

Previous studies of voluntary stepping in individuals with chronic stroke have found that decreased weight-bearing on the paretic limb before stepping was related to less propulsive force for forward momentum during paretic limb gait initiation. ${ }^{8}$ Reduced paretic limb propulsive force has also been reported to limit gait initiation speed when stepping with either limb, ${ }^{9}$ while first step characteristics can be altered to a greater extent for nonparetic limb stepping when the paretic side is in single-limb support. ${ }^{10}$ In reaction time stepping, step speed was observed to be slower in all step characteristics examined under single- and dual-task conditions for those with chronic stroke compared with controls. $^{11}$

More limited information about perturbation-induced stepping for balance recovery after stroke has indicated that evoked steps were initiated primarily with the nonparetic limb after a lean and release postural perturbation in individuals with subacute stroke. $^{12,13}$ Additionally, increased lower-limb motor recovery scores and initial weight-bearing on the nonparetic limb were related to increased frequency of paretic limb stepping. An acute stroke case study using the same approach to train protective stepping over 6 sessions plus physical therapy showed short-term improvements in stance-loading symmetry and faster speed of stepping. ${ }^{14}$ During inpatient stroke rehabilitation, increased fall rates were associated with increased use of external assistance and frequency of no-step trials, lower foot-floor clearance, and delayed time to initiate stepping responses. ${ }^{15}$ While these studies provide information about the types of changes in induced stepping, especially in the acute stages of recovery after stroke, a more comprehensive understanding of the specific impairments in protective stepping performance among chronic stroke survivors that can be targeted for rehabilitation interventions to improve balance and prevent falls is needed. Moreover, studies comparing voluntary and induced stepping performance in the same individuals poststroke could not be identified.

To address the foregoing issues, the purposes of this study were (1) to assess the induced stepping behavior of ambulatory

\begin{tabular}{|l|}
\hline List of abbreviations: \\
ANOVA analysis of variance \\
APA anticipatory postural adjustment \\
BOS base of support \\
COM center of mass \\
COP center of pressure \\
\hline
\end{tabular}

individuals with chronic stroke, and (2) to compare characteristics of waist-pull induced stepping responses with rapid voluntary stepping. We expected differences in performance between the legs for both stepping conditions, and that the subjects would use their nonparetic leg more often to initiate induced stepping. We also hypothesized that induced stepping would have faster, longer, and wider first steps overall, compared with voluntary stepping.

\section{Methods}

\section{Participants}

Ten participants poststroke, 4 men and 6 women (mean age \pm SD, $59.6 \pm 13.1 y$ ), were recruited from stroke groups and outpatient clinics at 1 site within a larger multisite intervention study. ${ }^{16}$ Chronicity of stroke averaged $2.9 \pm 1.1$ years, with $80 \%$ having right-sided weakness and ischemic stroke (table 1). All subjects gave informed consent, and the study was approved by the university's institutional review board.

\section{Experimental setup}

Participants stood naturally with each foot positioned on a separate force platform. Voluntary and perturbation-induced stepping were studied consecutively. Subjects took 3 voluntary steps forward as soon and as fast as they could in response to a light "go" cue that followed a warning light stimulus by a variable delay period. Three trials were recorded for steps initiated with the nonparetic leg followed by 3 trials with the paretic leg. For the perturbation condition, steps were induced by forward postural perturbations delivered by position-controlled, motordriven waist pulls $\left(9 \mathrm{~cm}, 18 \mathrm{~cm} / \mathrm{s}, 360 \mathrm{~cm} / \mathrm{s}^{2}\right) .{ }^{17}$ This pulling magnitude was selected based on previous studies ${ }^{1,17}$ showing that steps are normally induced in all subjects for most trials. A waist belt was snugly secured, and the pulling cable was attached in alignment with the umbilicus. Subjects wore a safety harness that prevented falls but otherwise did not restrict their movements. They received 9 randomly applied forward perturbations: three straight forward, three $30^{\circ}$ to the right, and three $30^{\circ}$ to the left. The three directions minimized prediction of the pull and assessed directional differences in balance recovery. Subjects were instructed to react naturally to prevent themselves from falling in response to the perturbation. A seated rest break was given between stepping conditions or whenever needed. Participants performed all trials without an assistive device and wore their foot orthosis.

\section{Data collection}

Ground reaction forces were recorded with 2 strain-gauge force platforms $^{\mathrm{a}}$ at $500 \mathrm{~Hz}$ for 5 seconds beginning 1 second before the perturbation or the "go" signal. The displacement of the net center of pressure (COP) was calculated to determine the APA characteristics. Body segment displacements were recorded using a 6-camera motion analysis system (Motus ${ }^{\mathrm{b}}$ ) that captured the motion of 17 markers over bilateral bony landmarks and the crown of the head. ${ }^{18}$ Data were collected for 5 seconds at $60 \mathrm{~Hz}$ and smoothed using a dual-pass (ie, zero-lag), seventh-order Butterworth low-pass filter with a cutoff frequency of $6 \mathrm{~Hz} .{ }^{19,20}$ 
Table 1 Subject characteristics

\begin{tabular}{llllllllll}
\hline Subject & Age $(\mathrm{y})$ & Sex & Years Poststroke & Paretic Side & Type of Stroke & BBS & 10-m Walk (s) & Assistive Device & Ankle-Foot Orthosis \\
\hline S1 & 83 & F & 4 & R & Unknown & 52 & 11.17 & None & None \\
S2 & 75 & F & 4 & R & Infarct & 32 & 57.92 & Quad cane & None \\
S3 & 62 & M & 3 & R & Infarct & 38 & 27.16 & None & None \\
S4 & 58 & F & 3 & R & Infarct & 39 & 18.65 & Single point & None \\
S5 & 60 & F & 3 & L & Infarct & 50 & 15.45 & Single point & Plastic rigid with hinge \\
S6 & 36 & M & 1 & R & Infarct & 54 & 11.46 & None & Plastic rigid with hinge \\
S7 & 59 & M & 4 & R & Infarct & 48 & 10.53 & None & None \\
S8 & 48 & M & 3 & R & Infarct & 55 & 14.03 & None & None \\
S9 & 52 & F & 1 & L & Hemorrhage & 56 & 11.88 & None & None \\
S10 & 63 & F & 3 & R & Infarct & 28 & 42.02 & Single point & Plastic rigid with hinge \\
\hline
\end{tabular}

Abbreviations: BBS, Berg Balance Scale; F, female; L, left; $M$, male; R, right.

\section{Data analyses}

Interactive graphical analysis programs (MatLab $6.0^{\mathrm{c}}$ ) were used to compute the APA characteristics and initial stepping responses. An APA was identified if there was an increase in the initial step side vertical force and simultaneous decrease in the stance side force with an initial shift in the net mediolateral COP toward the first stepping limb. The postural phase characteristics were derived from the net mediolateral COP displacement separated into 2 components: the thrust component, more generally referred as APA, characterized by an initial displacement of the COP toward the stepping leg; and the unloading component, characterized by a displacement of the COP toward the stance leg (fig 1). The onset was defined as the beginning of the COP displacement-that is, when the first derivative becomes continuously greater than zero. The APA amplitude was the maximum displacement of the net COP toward the stepping side, and thrust time was calculated from the onset to the time of the peak amplitude. The unloading time was calculated from the time of peak amplitude to foot liftoff, and the total postural phase duration was the sum of the thrust and unloading components.

The first step kinematic characteristics were identified from the ankle markers (see fig 1). Step duration was defined as the onset and end of the vertical velocity of the stepping side's marker. Step displacement was assessed by the anteroposterior (step length) and mediolateral (step width) displacement of the ankle marker, and step height by the maximum vertical displacement. The step global length was calculated as the square root of the sum of squares of the step width and length. Step onset time was calculated relative to the onset of the light cue or the perturbation.

\section{Statistical analyses}

An analysis of variance (ANOVA) of the perturbations by direction showed no difference $(P<.05)$ in the step characteristics for any of the variables; thus, the directions of perturbations were combined for the perturbation-induced stepping condition. Outcome measures were compared using 2-way repeatedmeasures ANOVAs, with type of stepping (voluntary or induced) and stepping leg (paretic or nonparetic) as the withinsubject factors. In cases of significance, the Tukey honestly significant difference post hoc test was used with the level of significance adjusted for multiple comparisons. A separate comparison of voluntary and induced straight forward stepping was made for APA characteristics using paired $t$ tests. An alpha level of $P<.05$ was selected for all statistical analyses (SPSS $18^{\mathrm{d}}$ ).

\section{Results}

\section{Stepping behavior during perturbation-induced trials}

All subjects stepped for all perturbation trials except 1 subject who did not step during 1 trial (table 2). Four subjects used just 1 step in at least 1 trial. No subjects required investigator assistance to maintain their balance. Overall, multiple steps were used $88.8 \%$ of the time to recover balance. Eight of the 10 subjects initiated stepping with both legs, and 2 subjects always stepped with their nonparetic leg. Across all trials, $35 \%$ of the steps were taken with the paretic leg, and $65 \%$ were taken with the nonparetic leg. For the diagonal pulls, when the perturbation was toward the paretic leg, $76.7 \%$ of the steps were taken with the opposite, passively unloaded nonparetic leg (see table 2). For perturbations toward the nonparetic leg, $51.7 \%$ were steps taken with the unloaded paretic leg.

\section{Step characteristics}

The first step duration was affected by the stepping condition's $\left(\mathrm{F}_{1,7}=23.216, \quad P<.002\right)$ being shorter for induced steps $(400 \pm 89 \mathrm{~ms})$ compared with voluntary steps $(642 \pm 166 \mathrm{~ms})$. A main effect of leg $\left(\mathrm{F}_{1,7}=10.855, P<.013\right)$ also indicated that step duration was longer for the paretic leg $(581 \pm 288 \mathrm{~ms})$ than for the nonparetic leg $(461 \pm 131 \mathrm{~ms})$. The marginal trend for an interaction $\left(\mathrm{F}_{1,7}=4.409, P=.074\right)$ did not reach significance, but the difference between legs showed a tendency to occur primarily during voluntary stepping (fig $2 \mathrm{~A}$ ). An effect of the stepping leg was also found for step height $\left(\mathrm{F}_{1,7}=209.52, P<.0001\right)$, whereby the nonparetic leg stepped higher for both stepping conditions $(18.2 \pm 1.9 \mathrm{~cm})$ compared with the paretic leg $(14.4 \pm 2.2 \mathrm{~cm})$ (fig 2B). There was no main effect of condition $\left(\mathrm{F}_{1,7}=.07\right.$, $P=.7954)$ or interaction $\left(\mathrm{F}_{1,7}=.0945, P=.767\right)$ for step height, and no main effect of condition $\left(\mathrm{F}_{1,7}=1.93, P=.207\right)$ or interaction $\left(\mathrm{F}_{1,7}=1.51, P=.2588\right)$ for step length. Step length tended to be greater for the nonparetic leg $(35.7 \mathrm{~cm} \pm 9.9)$ compared with the paretic leg $(30.0 \pm 11.7 \mathrm{~cm})\left(\mathrm{F}_{1,7}=5.4475, P=.0523\right)$.

Since the diagonal perturbations included a lateral component, an overall main effect of condition on step width was found $\left(\mathrm{F}_{1,7}=21.119, P<.003\right)$. Thus, the step width was greater during induced stepping $(6.8 \pm 3.3 \mathrm{~cm})$ than during voluntary stepping 
Induced stepping
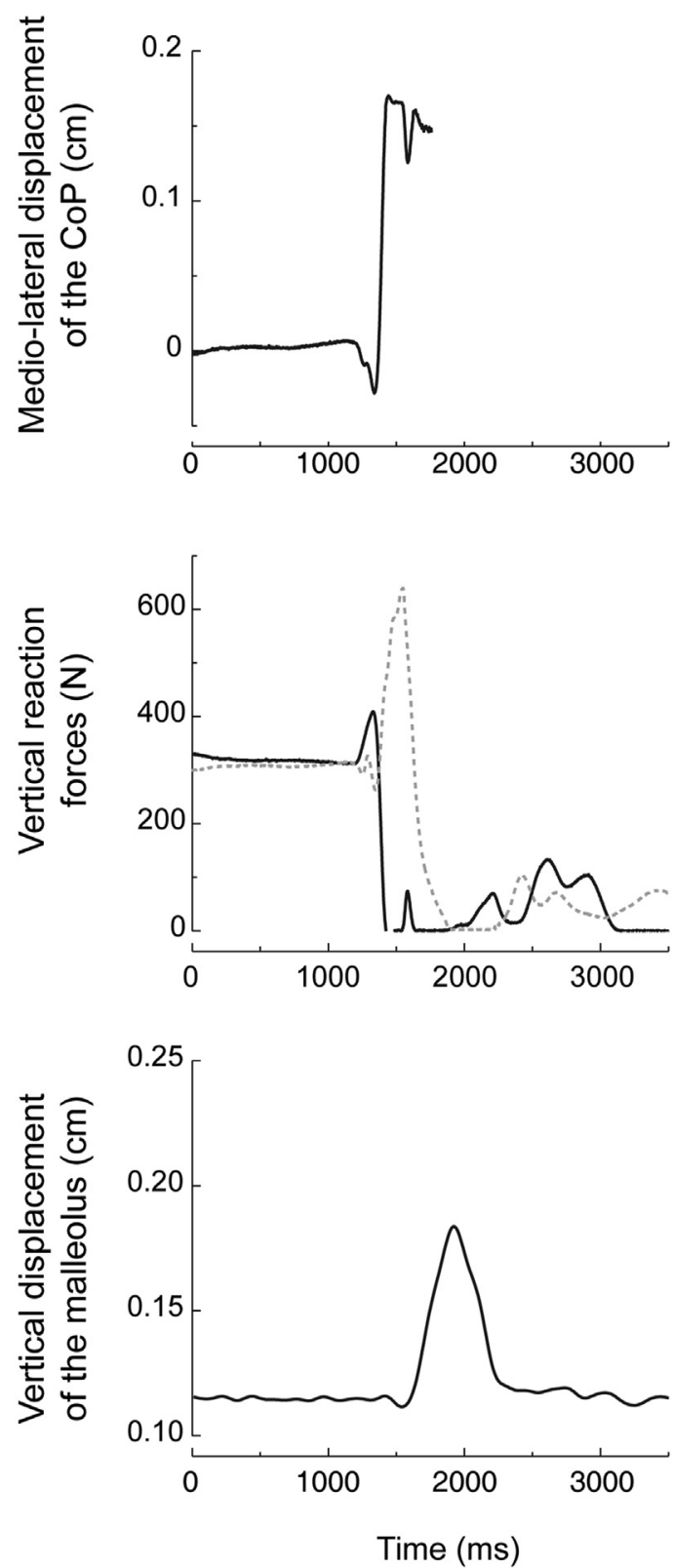

\section{Voluntary stepping}
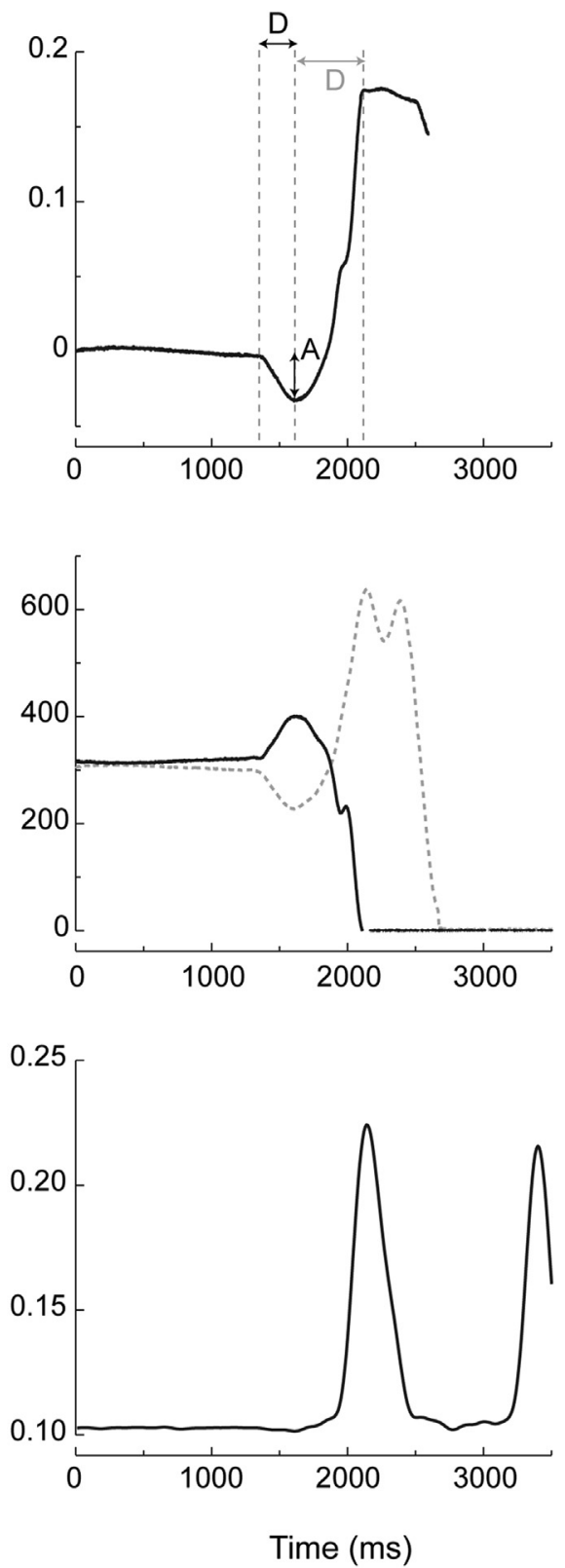

Fig 1 Example of trials. Representative examples of time histories from 1 subject during perturbation-induced stepping with the paretic leg (left) and voluntary stepping with the nonparetic leg (right). The top records show the mediolateral displacement of the COP from which the duration (D-black) and the amplitude (A-black) of the mediolateral APA thrust component and the duration (D-gray) of the unloading component were determined. The center records show the vertical ground reaction forces under the first stepping leg (black solid line) and the stance leg (gray dashed line). The bottom records show the vertical displacement of the malleolus marker of the stepping side from which the characteristics of the step were determined.

$(1 \pm 2.7 \mathrm{~cm})$. Global step length tended to be longer when subjects stepped with the nonparetic leg $(36.1 \pm 11.1 \mathrm{~cm})$ than when they stepped with the paretic leg $(31.2 \pm 10.4 \mathrm{~cm})\left(\mathrm{F}_{1,7}=5.106, P=.059\right)$. No main effect of condition $\left(\mathrm{F}_{1,7}=1.263, P=.298\right)$ or interaction $\left(\mathrm{F}_{1,7}=1.378, P=.279\right)$ was found for global length (fig $2 \mathrm{C}$ ).

For step onset time, there was a significant main effect of condition $\left(\mathrm{F}_{1,7}=11.413, P<.0118\right)$, with the step occurring earlier for induced stepping $(365 \pm 101 \mathrm{~ms})$ compared with voluntary stepping $(792 \pm 368 \mathrm{~ms})$. A main effect of the stepping leg $\left(\mathrm{F}_{1,7}=19.275, P<.0032\right)$ also indicated that the paretic leg initiated stepping $120 \mathrm{~ms}$ earlier than the nonparetic leg. Furthermore, there was a trend for an interaction between the 2 factors $\left(\mathrm{F}_{1,7}=5.128, P=.058\right)$, indicating that the difference between legs appeared to occur primarily for the voluntary condition (fig 3 ).

In order to identify the leg preference for stepping, we examined the interlimb load distribution before the perturbation (ie, $500 \mathrm{~ms}$ before the pull). In $20 \%$ of the trials, subjects had symmetrical weight distribution on each leg $(47 \%-53 \%$ of body weight). In these trials, the nonparetic leg initiated stepping $83 \%$ of the time. When the stepping leg supported less than $47 \%$ of 
Table 2 Induced step condition: number of balance recovery steps and initial stepping leg used for each perturbation direction

\begin{tabular}{|c|c|c|c|c|c|c|c|c|c|}
\hline \multirow[b]{2}{*}{ Subject } & \multicolumn{3}{|c|}{ No. of Steps } & \multicolumn{2}{|c|}{ Forward Pulls } & \multicolumn{2}{|c|}{ Pull on Nonparetic } & \multicolumn{2}{|c|}{ Pull on Paretic } \\
\hline & 1 & 2 & 3 & $\mathrm{P}$ & $\mathrm{NP}$ & US (P) & LS (NP) & US (NP) & LS (P) \\
\hline S1 & & 88.9 & 11.1 & 66.7 & 33.3 & 100.0 & & 66.7 & 33.3 \\
\hline S2 & & 44.4 & 55.5 & 100 & & 100.0 & & 66.7 & 33.3 \\
\hline S3 & 33.3 & 33.3 & 33.3 & & 100 & 66.7 & 33.3 & 100.0 & \\
\hline S4 & & 44.4 & 55.5 & 33.3 & 66.7 & 66.7 & 33.3 & 100.0 & \\
\hline S5 & & 88.9 & 11.1 & & 100 & 33.3 & 66.7 & 33.3 & 66.7 \\
\hline S6 & 50.0 & 25.0 & 25.0 & & 100 & & 66.7 & 100.0 & \\
\hline S7 & & 33.3 & 66.6 & 33.3 & 66.7 & & 100.0 & 66.7 & 33.3 \\
\hline S8 & 22.2 & 66.7 & 11.1 & & 100 & & 100.0 & 100.0 & \\
\hline S9 & 11.1 & 88.9 & 0.0 & 66.7 & 33.3 & 100.0 & & 33.3 & 66.7 \\
\hline \multirow[t]{2}{*}{ S10 } & & 11.1 & 88.9 & 33.3 & 66.7 & 33.3 & 66.7 & 100.0 & \\
\hline & 27.8 & 52.2 & 35.6 & 33.3 & 66.7 & 51.7 & 48.3 & 76.7 & 23.3 \\
\hline
\end{tabular}

NOTE. Values are percentages.

Abbreviations: LS, loaded step; NP, nonparetic leg; P, paretic leg; US, unloaded step.

body weight ( $51 \%$ of trials), the nonparetic leg was used $42 \%$ and the paretic leg $58 \%$ of the time. For the 26 trials (29\% of trials) where the stepping leg supported more than $53 \%$ of body weight, $88.5 \%$ of the steps were initiated with the nonparetic leg.

\section{Postural phase characteristics}

Because the diagonal pulls can influence the APA characteristics through passive contributions to limb loading, only the straight forward direction trials were analyzed. In the straight forward induced trials, only 5 subjects stepped with their paretic leg, and only 3 of these subjects had APAs. Therefore, the APA analysis was focused on comparing the postural phase characteristics only for the nonparetic leg trials $(n=9,1$ subject had no APA for these induced trials) between straight forward induced stepping and voluntary stepping. For perturbation stepping with the nonparetic leg, APAs occurred in $75 \%$ of the trials compared with $100 \%$ of the voluntary stepping trials.

The total postural phase duration (fig 4) was longer for voluntary stepping $(597 \pm 195 \mathrm{~ms})$ than induced straight forward stepping $(344 \pm 112 \mathrm{~ms})$ (paired $t$ test: $\left.t_{8}=3.22, P<.012\right)$. This difference was due primarily to the unloading component, which was shorter for induced stepping $(181 \pm 65 \mathrm{~ms})$ compared with voluntary stepping $(359 \pm 188 \mathrm{~ms}) \quad\left(t_{8}=3.076, P<.015\right)$. APA amplitude $\left(t_{7}=.93\right.$, $P=.383$ ) was not different between conditions.

\section{Discussion}

The present results provide new details about the kinetic and kinematic performance of individuals with chronic stroke during the initiation of rapid, visually cued voluntary stepping and perturbation-induced stepping. For perturbation trials, participants maintained their balance without investigator assistance by stepping with either their nonparetic or paretic leg. Overall, multiple induced steps occurred in about $90 \%$ of the trials. Eight of the 10 subjects initiated stepping with both legs, and 2 subjects always stepped with their nonparetic leg. Furthermore, induced steps occurred earlier and were faster than rapid voluntary steps, the duration of the APA postural phase was shorter for induced stepping, and first step height was greater with the nonparetic leg. These results highlight both differences and similarities in initiating and executing rapid voluntary and perturbation-induced stepping in relation to the paretic and nonparetic lower limbs.

\section{Induced step behavior}

Similar to healthy older adults, individuals with chronic stroke executed more multiple recovery steps than single steps with a perturbation magnitude smaller than that used previously with healthy individuals. ${ }^{18}$ Sensorimotor impairments are common among older adults and after stroke, so it is not surprising that multiple steps were prevalent. Stabilizing balance with 1 step involves precisely stopping body motion relative to the changing BOS at step landing. For healthy adults, a reduced stability margin and greater knee flexion at foot contact distinguished between single and multiple recovery steps. ${ }^{21}$ In our study, $90 \%$ of single-step trials involved the nonparetic leg, which has better neuromuscular control to perform single-step balance recovery. Of note, the 1 individual who used a single paretic leg step had a maximum Berg Balance Scale score and one of the fastest gait speeds among the cohort, which indicates less motor impairment of the paretic leg.

It was anticipated that forward diagonal perturbations would involve stepping with the passively unloaded leg on the opposite side. This was mostly seen when the nonparetic leg $(76.7 \%$ of trials) compared with the paretic leg $(51.7 \%$ of trials) was unloaded. However, the use of the paretic leg was greater when that leg was passively unloaded compared with the straight forward perturbations $(51.7 \%$ vs $33 \%$ ). The diagonal perturbations may explain the overall larger percentage $(80 \%)$ of individuals in this study who stepped with both the paretic and nonparetic leg compared with the smaller percentage (45\%) observed during a forward lean perturbation. ${ }^{12}$ This difference indicates that the perturbation direction may be a useful way to encourage or force forward stepping with the paretic leg, and that chronic stroke survivors may possibly have a more adaptable induced stepping capacity then those with subacute stroke.

\section{Comparison of induced and voluntary stepping}

The earlier and faster induced stepping resembles that observed in healthy older adults. ${ }^{7,22,23}$ Although voluntary steps have been shown to be slower in older individuals, induced steps have also 


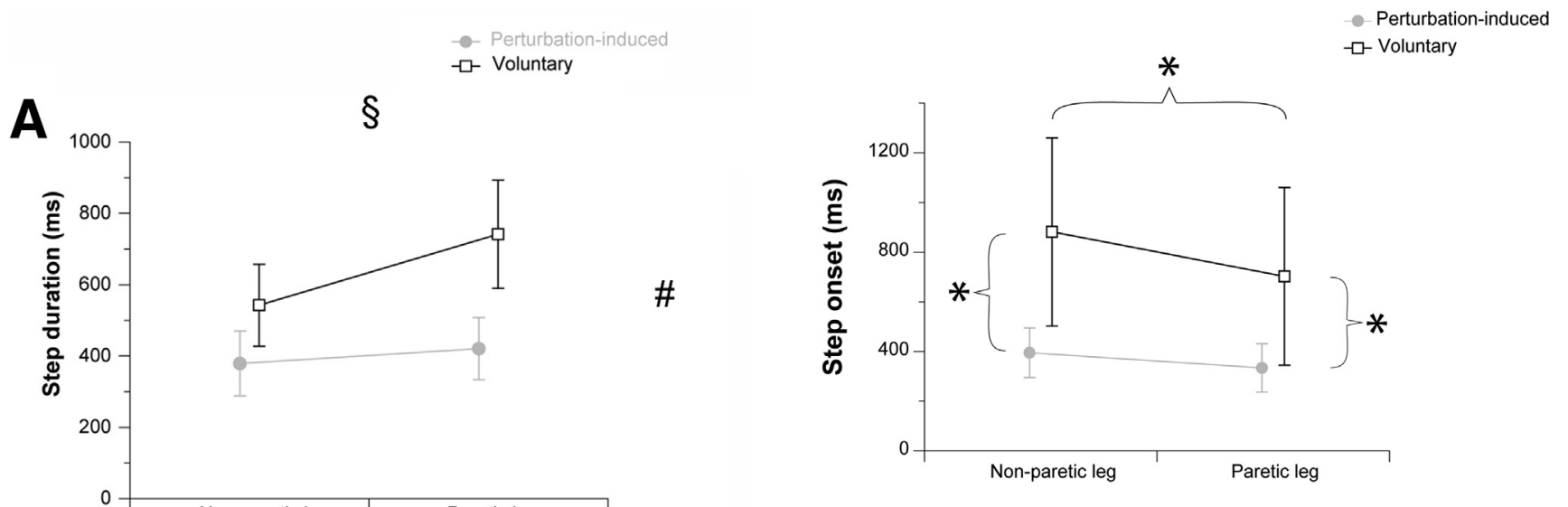

B

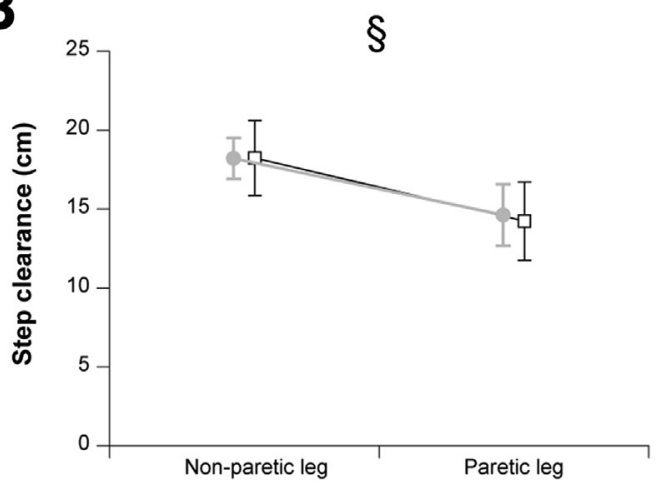

C

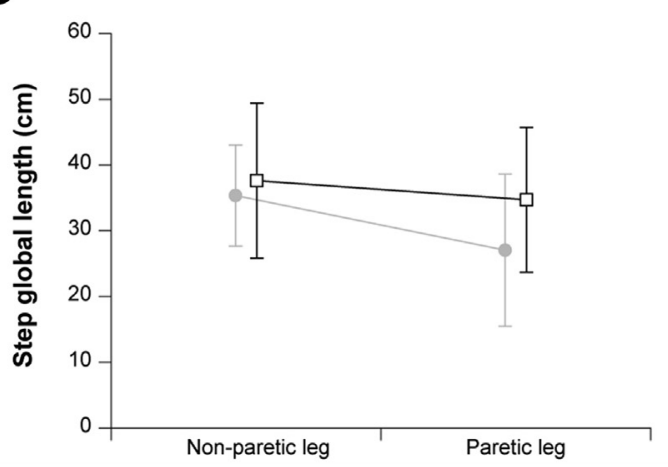

Fig 2 Step characteristics. Group mean values ( \pm SD) for voluntary (black open squares) and induced stepping (gray circles) conditions for (A) step duration, (B) step clearance, and (C) step global length. \#Significant difference between conditions of stepping (voluntary vs

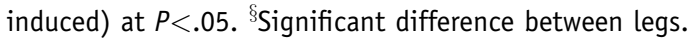

been shown to be as fast as those for younger individuals. ${ }^{4,23,24}$ Past studies ${ }^{25-27}$ have shown that task-specific practice training can enhance movement performance in stroke patients. Hence, the faster induced steps in this study may indicate the potential for enhancing voluntary stepping through repetitive induced step training as demonstrated in older adults ${ }^{28}$ and in individuals with Parkinson's disease. ${ }^{29}$ The ability to rapidly place the foot in the appropriate location to reconfigure the BOS relative to the moving COM is a key aspect of reactive balance control for safe community ambulation. Therefore, induced step training should be considered for inclusion in balance rehabilitation programs for individuals poststroke.
Fig 3 Step onset. Group mean values $( \pm S D$ ) for voluntary (black open squares) and induced stepping (gray circles) conditions for step onset time relative to the perturbation onset or light cue onset. ${ }^{*} \mathrm{~A}$ difference between condition and leg at $P<.05$ (Tukey honestly significant difference).

\section{Stepping leg performance}

Step height and, marginally, global step length were greater for the nonparetic leg compared with the paretic leg across stepping conditions. This is consistent with the differences in motor control ability between sides of the body after stroke. ${ }^{10,30}$ The slower nonparetic step onset reflects the interdependence of interlimb swing and stance functions. Stepping with the nonparetic leg requires weight transfer and balancing onto the paretic leg, which is difficult after stroke. The shorter nonparetic leg step duration may also indicate the need to rapidly return the foot to the ground for stability because of ineffective weight transfer. Given the asymmetrical weight-bearing posture after stroke and the fact that step onset may normally depend on the amount of weight on the leg, ${ }^{31}$ the increased weight on the nonparetic leg and step with the paretic leg may offer a timing advantage in the use of the paretic leg but not in the use of the nonparetic leg. The trend for an

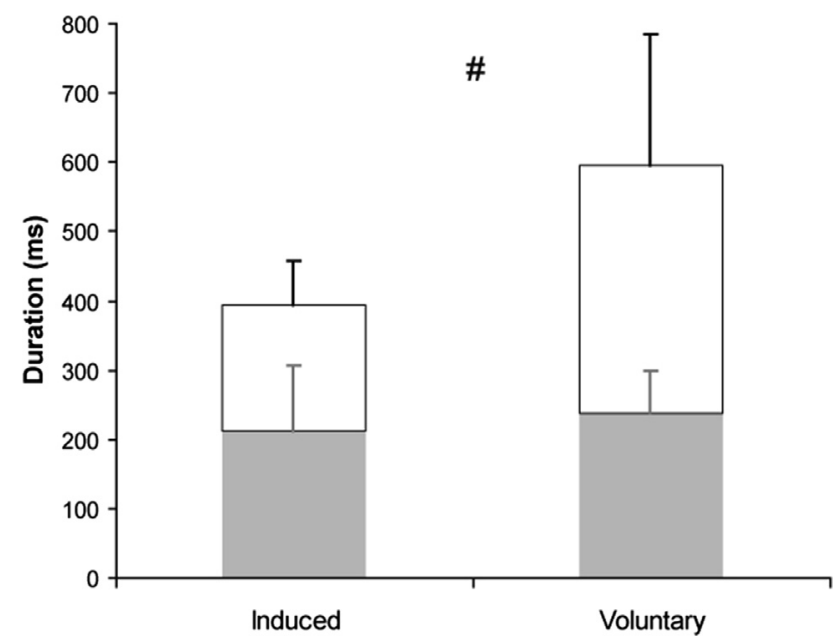

Fig 4 Nonparetic leg postural phase duration. The mean values $( \pm S D)$ for thrust phase (gray) and unloading phase (white) are presented for the nonparetic leg during rapid voluntary stepping and induced straight forward stepping conditions. "Significant difference for the unloading phase between stepping conditions at $P<.05$. 
interaction suggested that there was less difference in induced step onset timing between the legs than for voluntary stepping. This may be because the diagonal perturbations likely assisted the weight transfer and thus reduced the timing difference between the 2 legs by facilitating stepping with each leg.

\section{Postural phase characteristics}

The inconsistent presence of APAs for induced stepping is similar to findings in previous work showing that APAs are often normally absent or diminished during induced stepping compared with voluntary stepping, suggesting that securing mediolateral stability before unplanned stepping may be less of a priority than for planned stepping. ${ }^{4,32}$ The longer voluntary postural phase duration is primarily due to the prolonged unloading component. This may reflect the more rapid return of the stepping limb to the ground as a strategy to minimize the time spent in the unstable single-limb support phase of rapid induced stepping compared with slower voluntary stepping.

\section{Study limitations}

This study was an initial effort to determine participant tolerance and response to challenging balance perturbations, and it is limited by the sample size and number of trials. The limited number of loaded and unloaded steps with the paretic and nonparetic legs restricted further analysis of the induced step trials with each leg. However, as the study was focused on the subjects' natural, selfselected induced stepping behavior, the findings reflected their preferred or achievable performance. Although 3 forward directions were used, the predictability of only forward perturbations may have impacted the results. Motor function and spasticity were not assessed, and manipulation of the initial weight-bearing conditions was not systematically controlled in order to study the effects of natural standing posture. These factors may have influenced the selection of the stepping leg, as previously noted in a retrospective chart review ${ }^{12}$ of persons poststroke studied in an inpatient setting, and need further investigation.

\section{Conclusions}

The ability to effectively execute protective stepping is important for balance control and preventing falls. People with chronic stroke can execute induced steps with either their paretic or nonparetic leg for multidirectional forward perturbations. The faster induced stepping compared with instructed voluntary stepping may indicate an inherent capacity to train the system to produce quicker reactive voluntary steps through induced step training. Use of forward diagonal perturbations, and possibly other directions, may help to force stepping with the paretic leg. Further studies should identify the limitations in protective stepping performance of paretic and nonparetic legs involving other directions and postural perturbation magnitudes, and in relation to different impairment profiles, functional levels, and periods of chronicity after stroke.

\section{Suppliers}

a. AMTI, 176 Waltham St, Watertown, MA 02472-4800.

b. Peak Performance, 4920 Atlanta Hwy, Alpharetta, GA, 30004. c. MathWorks, Inc, 3 Apple Hill Dr, Natick, MA 01760-2098.

d. SPSS Inc, 233 S Wacker Dr, 11th Fl, Chicago, IL 60606.

\section{Keywords}

Postural balance; Rehabilitation; Stroke

\section{Corresponding author}

Katherine M. Martinez, PT, MA, Department of Physical Therapy and Human Movement Sciences, Feinberg School of Medicine, Northwestern University, Ste 1100, 645 N Michigan Ave, Chicago, IL 60611. E-mail address: k-martinez@northwestern.edu.

\section{References}

1. Pai YC, Rogers MW, Patton J, Cain TD, Hanke TA. Static versus dynamic predictions of protective stepping following waist-pull perturbations in young and older adults. J Biomech 1998;31:1111-8.

2. Maki B, McIlroy W. Change-in-support balance reactions in older persons: an emerging research area of clinical importance. Neurol Clin 2005;23:751-83.

3. Rogers MW, Martinez KM. Recovery and rehabilitation of standing balance after stroke. In: Stein J, Harvey R, Macko R, Winstein C, Zorowitz R, editors. Stroke recovery and rehabilitation. 1st ed. New York: Demos Medical; 2009. p 343-74.

4. Rogers MW, Hedman LD, Johnson ME, Cain TD, Hanke TA. Lateral stability during forward-induced stepping for dynamic balance recovery in young and older adults. J Gerontol A Biol Sci Med Sci 2001;56:M589-94.

5. Lord SR, Fitzpatrick RC. Choice stepping reaction time: a composite measure of falls risk in older people. J Gerontol A Biol Sci Med Sci 2001;56:M627-32.

6. Weerdesteyn V, de Niet M, van Duijnhoven HJR, Geurts ACH. Falls in individuals with stroke. J Rehabil Res Dev 2008;45:1195-213.

7. Luchies CW, Wallace D, Pazdur R, Young S, DeYoung AJ. Effects of age on balance assessment using voluntary and involuntary step tasks. J Gerontol A Biol Sci Med Sci 1999;54:M140-4.

8. Brunt D, Vander Linden DW, Behrman AL. The relation between limb loading and control parameters of gait initiation in persons with stroke. Arch Phys Med Rehabil 1995;76:627-34.

9. Tokuno CD, Eng JJ. Gait initiation is dependent on the function of the paretic trailing limb in individuals with stroke. Gait Posture 2006;24: 424-8.

10. Hesse S, Reiter F, Jahnke M, Dawson M, Sarkodie-Gyan T, Mauritz KH. Asymmetry of gait initiation in hemiparetic stroke subjects. Arch Phys Med Rehabil 1997;78:719-24.

11. Melzer I, Tzedek I, Or M, et al. Speed of voluntary stepping in chronic stroke survivors under single- and dual-task conditions: a case-control study. Arch Phys Med Rehabil 2009;90:927-33.

12. Mansfield A, Inness EL, Lakhani B, McIlroy WE. Determinants of limb preference for initiating compensatory stepping poststroke. Arch Phys Med Rehabil 2012;93:1179-84.

13. Lakhani B, Mansfield A, Inness EL, McIlroy WE. Compensatory stepping responses in individuals with stroke: a pilot study. Physiother Theory Pract 2011;27:299-309.

14. Mansfield A, Inness EL, Komar J, et al. Training rapid stepping responses in an individual with stroke. Phys Ther 2011;91:958-69.

15. Mansfield A, Inness EL, Wong JS, Fraser JE, McIlroy WE. Is impaired control of reactive stepping related to falls during inpatient stroke rehabilitation? Neurorehabil Neural Repair 2013;27:526-33.

16. Sullivan KJ, Brown DA, Klassen T, et al. Effects of task-specific locomotor and strength training in adults who were ambulatory after 
stroke: results of the STEPS randomized clinical trial. Phys Ther 2007; 87:1580-602.

17. Pidcoe PE, Rogers MW. A closed-loop stepper motor waist-pull system for inducing protective stepping in humans. J Biomech 1998;31:377-81.

18. Mille M-L, Johnson ME, Martinez KM, Rogers MW. Age-dependent differences in lateral balance recovery through protective stepping. Clin Biomech (Bristol, Avon) 2005;20:607-16.

19. Robertson DGE, Dowling JJ. Design and responses of Butterworth and critically damped digital filters. J Electromyogr Kinesiol 2003;13:569-73.

20. Winter DA. Biomechanics and motor control of human movement. 4th ed. Hoboken: Wiley; 2009. Available at: http://dx.doi.org/10.1002/ 9780470549148. Accessed April 12, 2013.

21. Carty CP, Mills P, Barrett R. Recovery from forward loss of balance in young and older adults using the stepping strategy. Gait Posture 2011; 33:261-7.

22. McIlroy WE, Maki BE. Age-related changes in compensatory stepping in response to unpredictable perturbations. J Gerontol A Biol Sci Med Sci 1996;51:M289-96.

23. Burleigh A, Horak FB. Influence of instruction, prediction, and afferent sensory information on the postural organization of step initiation. J Neurophysiol 1996;75:1619-28.

24. Luchies CW, Alexander NB, Schultz AB, Ashton-Miller J. Stepping responses of young and old adults to postural disturbances: kinematics. J Am Geriatr Soc 1994;42:506-12.

25. Richards CL, Malouin F, Wood-Dauphinee S, Williams JI, Bouchard JP, Brunet D. Task-specific physical therapy for optimization of gait recovery in acute stroke patients. Arch Phys Med Rehabil 1993;74:612-20.

26. Salbach NM, Mayo NE, Wood-Dauphinee S, Hanley JA, Richards CL, Côté R. A task-orientated intervention enhances walking distance and speed in the first year post stroke: a randomized controlled trial. Clin Rehabil 2004;18:509-19.

27. Dean CM, Richards CL, Malouin F. Task-related circuit training improves performance of locomotor tasks in chronic stroke: a randomized, controlled pilot trial. Arch Phys Med Rehabil 2000;81:409-17.

28. Rogers MW, Johnson ME, Martinez KM, Mille M-L, Hedman LD. Step training improves the speed of voluntary step initiation in aging. J Gerontol A Biol Sci Med Sci 2003;58:46-51.

29. Jöbges M, Heuschkel G, Pretzel C, Illhardt C, Renner C, Hummelsheim H. Repetitive training of compensatory steps: a therapeutic approach for postural instability in Parkinson's disease. J Neurol Neurosurg Psychiatry 2004;75:1682-7.

30. Melzer I, Goldring M, Melzer Y, Green E, Tzedek I. Voluntary stepping behavior under single- and dual-task conditions in chronic stroke survivors: a comparison between the involved and uninvolved legs. J Electromyogr Kinesiol 2010;20:1082-7.

31. Mille ML, Mouchnino L. Are human anticipatory postural adjustments affected by a modification of the initial position of the center of gravity? Neurosci Lett 1998;242:61-4.

32. McIlroy WE, Maki BE. The control of lateral stability during rapid stepping reactions evoked by antero-posterior perturbation: does anticipatory control play a role? Gait Posture 1999;9:190-8. 